\title{
Comportamento ingestivo e respostas fisiológicas de novilhos submetidos a dietas com torta de amendoim
}

\author{
[Intake behavior and physiological responses of steer fed with peanut cake diets] \\ P.A. Oliveira ${ }^{1}$, R.L. Oliveira ${ }^{2}$, G.G.P. Carvalho $^{2}$, O.L. Ribeiro ${ }^{2}$, M.C.P. Leite ${ }^{3}$, B.R. Correia ${ }^{1}$, \\ A.C. Ferreira ${ }^{4}$, N.B. Santana Filho ${ }^{4}$ \\ ${ }^{1}$ Aluno de pós-graduação - UESB - Itapetinga, BA \\ ${ }^{2}$ Universidade Federal da Bahia - UFBA - Salvador, BA \\ ${ }^{3}$ Universidade Federal do Recôncavo da Bahia - UFRB - Cruz das Almas, BA \\ ${ }^{4}$ Aluno de pós-graduação - Universidade Federal da Bahia - UFBA - Salvador, BA
}

\begin{abstract}
RESUMO
Objetivou-se avaliar a substituição do farelo de soja por torta de amendoim no concentrado da dieta de novilhos, por meio do comportamento ingestivo e respostas fisiológicas. Foram utilizados cinco novilhos, dispostos em um quadrado latino 5 x 5 . As dietas foram compostas de feno de tifton, milho moído, farelo de soja e torta de amendoim, constituídas de zero (100\% de farelo de soja), 25, 50, 75 e 100\% de substituição por torta de amendoim no concentrado. Os níveis de torta de amendoim não influenciaram $(\mathrm{P}>0,05)$ as eficiências de ingestão e ruminação da matéria seca e da fibra em detergente neutro. Em relação às atividades comportamentais, o único parâmetro em que se observou efeito da substituição foi o número de períodos de ócio no turno da manhã $(\mathrm{P}<0,05)$, no qual se constatou efeito linear crescente. A taxa de secreção salivar e a quebra de partículas foram semelhantes, pois não houve efeito $(\mathrm{P}>0,05)$ das dietas sobre as características de mastigação. Como não houve efeito $(\mathrm{P}>0,05)$ das dietas sobre as frequências respiratória, cardíaca e a temperatura retal, o calor endógeno produzido pela fermentação ruminal foi equivalente. A torta de amendoim, por conter aflatoxinas, quando fornecida em alta relação volumoso x concentrado, pode substituir o farelo de soja na dieta de novilhos, pois ocasiona comportamento ingestivo e respostas fisiológicas semelhantes.
\end{abstract}

Palavras-chave: atividades comportamentais, parâmetros fisiológicos, ruminantes, tortas de oleaginosas

\begin{abstract}
This study aimed to evaluate the replacement of soybean meal with peanut cake in the concentrate of steer diets through intake behavior and physiological responses. Five steers, arranged in a $5 x 5$ latin square design were used. The diets were composed of Tifton hay, ground corn, soybean meal and peanut cake, made from zero (100\% soybean meal), 25, 50, 75 and 100\% replacement for peanut cake in the concentrate. The levels of peanut cake did not influence $(P>0.05)$ the intake and rumination efficiencies of dry matter and fiber in neutral detergent. Regarding the behavioral activities, the only parameter that observed a substitution effect was the number of idle periods in the morning shift $(P<0.05)$ which had an increasing linear effect. The rate of salivary secretion and the particle breakdown were similar, because there was no effect $(P>0.05)$ of the diets on the chewing characteristics. As there was no effect $(P>0.05)$ of the diets on the respiratory rate, heart rate and rectal temperature, the endogenous heat produced by rumen fermentation was equivalent. The peanut cake, by containing aflatoxin, when provided in high roughage $x$ concentrate rate, can replace soybean meal in the steers' diet because it causes similar intake behavior and physiological responses.
\end{abstract}

Keywords: behavioral activities, physiological parameters, ruminant animals, oleaginous plants cakes

\section{INTRODUÇÃO}

Alimentos alternativos estão sendo testados para substituir aquele considerado padrão das

Recebido em 27 de julho de 2013

Aceito em 18 de dezembro de 2013

E-mail: pazootecnista@gmail.com misturas concentradas da dieta de ruminantes. As tortas de oleaginosas constituem alternativa de substituição do ingrediente proteico do concentrado formulado à base de farelo de soja (Correia et al., 2011). 
O comportamento alimentar tem sido estudado com relação às características dos alimentos, à motilidade do pré-estômago e ao ambiente (Macedo Júnior et al., 2009). As mastigações merícicas são medidas utilizadas para avaliação das características físicas dos alimentos, pois estão relacionadas à redução do tamanho das partículas (Mendes Neto et al., 2007). As tortas de oleaginosas possuem características físicas e químicas intrínsecas, desta forma as atividades comportamentais podem indicar a aceitabilidade e o valor nutricional dos alimentos para nutrição de ruminantes.

As adversidades climáticas podem provocar alterações nos processos fisiológicos, como temperatura corporal e retal, frequência respiratória e cardíaca (Ferreira et al., 2006). As respostas fisiológicas são resultado da interação do ambiente com a dieta, pois o consumo de nutriente dos animais pelo alimento fornecido pode ser direcionado aos mecanismos de manutenção do equilíbrio da temperatura corporal.

Objetivou-se avaliar o efeito da substituição do farelo de soja por torta de amendoim no concentrado da dieta por intermédio do comportamento ingestivo e respostas fisiológicas de novilhos.

\section{MATERIAL E MÉTODOS}

O experimento foi realizado na Fazenda Experimental da Universidade Federal da Bahia, localizada a $12^{\circ} 23^{\prime} 57.51^{\prime \prime}$ na latitude sul e $38^{\circ}$ 52' 44.66" na longitude oeste, no município de São Gonçalo dos Campos-BA. O clima, de acordo com a classificação de Köppen, é do tipo As ("A": clima tropical, com temperatura média do mês mais frio sempre superior a $18^{\circ} \mathrm{C}$, e "s": estação seca no período de sol mais alto e dias mais longos) e precipitação com cerca de $1.000 \mathrm{~mm}$ de chuva.

Foram utilizados cinco novilhos, castrados, com peso corporal médio de $550 \mathrm{~kg}$, distribuídos em um quadrado latino (QL) $5 \times 5$, com cinco períodos constituídos de 11 dias e cinco dietas contendo níveis de substituição do farelo de soja por torta de amendoim no concentrado (Tab. 1). A mistura mineral foi fornecida à vontade.

$\mathrm{Na}$ Tab. 2 consta a composição centesimal e a nutricional dos ingredientes, e na Tab. 3 das dietas na forma de mistura total.

Tabela 1. Composição dos ingredientes (\% dieta total) das dietas experimentais

\begin{tabular}{lccccc}
\hline \multirow{2}{*}{ Ingrediente } & \multicolumn{5}{c}{ Níveis de substituição do farelo de soja por torta de amendoim no } \\
& 0 & 25 & 50 & 75 & 100 \\
\cline { 2 - 6 } & 14 & 14 & 14 & 14 & 14 \\
\hline Milho moído & 16 & 12 & 8 & 4 & 0 \\
Farelo de soja & 0 & 4 & 8 & 12 & 16 \\
Torta de amendoim & 70 & 70 & 70 & 70 & 70 \\
Feno de tifton-85 & & & & \\
\hline
\end{tabular}

Tabela 2. Composição nutricional (\% MS) dos alimentos das dietas experimentais

\begin{tabular}{|c|c|c|c|c|}
\hline \multirow[b]{2}{*}{ Fração analítica } & \multicolumn{4}{|c|}{ Ingredientes } \\
\hline & $\begin{array}{c}\text { Feno de } \\
\text { tifton }\end{array}$ & $\begin{array}{l}\text { Milho } \\
\text { moído }\end{array}$ & $\begin{array}{c}\text { Farelo de } \\
\text { soja }\end{array}$ & $\begin{array}{c}\text { Torta de } \\
\text { amendoim }\end{array}$ \\
\hline Matéria seca (\%) & 86,42 & 93,40 & 89,75 & 89,53 \\
\hline Matéria mineral $^{1}$ & 7,89 & 1,41 & 6,54 & 6,45 \\
\hline Proteína bruta ${ }^{1}$ & 6,14 & 6,18 & 45,77 & 44,84 \\
\hline Extrato etéreo $^{1}$ & 1,78 & 5,79 & 3,49 & 9,56 \\
\hline Fibra em detergente neutro ${ }^{1,2}$ & 74,85 & 14,69 & 11,08 & 13,41 \\
\hline Carboidratos não fibrosos 1 & 9,34 & 71,93 & 33,12 & 25,74 \\
\hline Lignina ${ }^{1}$ & 8,28 & 2,17 & 1,97 & 2,91 \\
\hline Micotoxinas $^{3}$ & ND & ND & ND & 22,18 \\
\hline
\end{tabular}


Tabela 3. Composição nutricional (\% MS) das dietas experimentais

\begin{tabular}{|c|c|c|c|c|c|}
\hline \multirow{2}{*}{$\begin{array}{l}\text { Fração } \\
\text { analítica }\end{array}$} & \multicolumn{5}{|c|}{$\begin{array}{l}\text { Níveis de substituição do farelo de soja por torta de amendoim } \\
(\%)\end{array}$} \\
\hline & 0 & 25 & 50 & 75 & 100 \\
\hline Matéria seca (\%) & 87,93 & 87,92 & 87,91 & 87,90 & 87,89 \\
\hline Matéria mineral $^{1}$ & 6,77 & 6,76 & 6,76 & 6,76 & 6,75 \\
\hline Proteína bruta ${ }^{1}$ & 12,49 & 12,45 & 12,41 & 12,37 & 12,34 \\
\hline Extrato etéreo ${ }^{1}$ & 2,62 & 2,86 & 3,10 & 3,34 & 3,59 \\
\hline Fibra em detergente neutro ${ }^{1,2}$ & 56,22 & 56,32 & 56,41 & 56,50 & 56,60 \\
\hline Carboidratos não fibrosos 1 & 21,91 & 21,61 & 21,32 & 21,02 & 20,73 \\
\hline Lignina $^{1}$ & 6,42 & 6,45 & 6,49 & 6,53 & 6,57 \\
\hline Nutrientes digestíveis totais ${ }^{1}$ & 60,54 & 60,79 & 61,02 & 61,23 & 61,48 \\
\hline Micotoxinas $^{3}$ & ND & 0,89 & 1,77 & 2,66 & 3,55 \\
\hline
\end{tabular}

Os novilhos foram alojados em baias individuais de $3,0 \times 6,0 \mathrm{~m}$, dotadas de cocho, saleiro e bebedouro. $\mathrm{O}$ arraçoamento foi realizado as nove e às 16 horas, com ajuste diário para possibilitar 10 a $20 \%$ de sobras. O consumo diário foi mensurado por meio de pesagem do alimento fornecido e das respectivas sobras, por animal, em cada período.

A determinação do teor de matéria seca (MS), matéria mineral $(\mathrm{MM})$, proteína bruta $(\mathrm{PB}) \mathrm{e}$ extrato etéreo (EE) dos ingredientes das dietas foram realizados segundo métodos da AOAC (Official..., 1995). A fibra em detergente neutro (FDN) e a lignina foram realizadas de acordo com o método descrito por Van Soest et al. (1991). A porcentagem de carboidratos não fibrosos (CNF) foi obtida pela equação de Sniffen et al. (1992): CNF (\%MS) $=100-(\%$ $\mathrm{MM}+\% \mathrm{~PB}+\% \mathrm{EE}+\% \mathrm{FDN})$.

Os nutrientes digestíveis totais (NDT) foram cálculados de acordo com a seguinte fórmula (Nutrient..., 2001): \%NDT $=\%$ CNF-d + \%PB-d $+(\%$ AG-d $\times 2,25)+\%$ FDNn-d -7.

A determinação de micotoxinas nos ingredientes das dietas foi realizada por meio de extração, clarificação e derivação $100 \%$ automatizada, análise por cromatografia líquida de alta eficiência (HPLC) e cromatografia líquida acoplada à espectrometria de massa/massa para TRCs (LCMS/MS).

No $10^{\circ}$ dia do período experimental, os animais foram submetidos à avaliação visual, durante $24 \mathrm{~h}$, em intervalos de cinco minutos, para determinação do tempo despendido em ingestão, ruminação e ócio (Johnson e Combs, 1991) nos turnos da manhã (6h05 às 12h); tarde (12h05 às $18 \mathrm{~h})$; noite (18h05 às $24 \mathrm{~h})$ e madrugada (00h05 às 6h). Durante as observações noturnas, o ambiente foi mantido com iluminação artificial.

Procedeu-se à observação de nove bolos ruminais por animal em três turnos para contagem do número de mastigações merícicas e do tempo de mastigações merícicas de cada bolo obtidos simultaneamente, utilizando-se um cronômetro digital.

O número de bolos ruminados por dia (NBRd $\mathrm{n} \%$ dia), o tempo de mastigação total (TMT $\mathrm{min} / \mathrm{dia}$ ), as eficiências de ingestão (EI $\mathrm{kg}$ ingerido/h) e de ruminação (ERU kg ruminado/h) da MS e da FDN foram calculados conforme metodologia descrita em Burger et al. (2000), por intermédio das seguintes equações:

NBRd $=$ TRU/TMMb;

TRU = tempo total de ruminação por dia (s/dia);

$\mathrm{TMMb}=$ tempo médio de mastigações merícicas por bolo ruminal (s/bolo);

$\mathrm{TMT}=\mathrm{TI}+\mathrm{TRU}$;

$\mathrm{TI}=$ tempo gasto em ingestão diariamente (h);

TRU = tempo gasto em ruminação diariamente (h);

EIMS $=$ CMS $/ \mathrm{TI}$

EIFDN $=$ CFDN/TI;

ERUMS = CMS/TRU;

ERUFDN = CFDN/TRU;

CMS = consumo diário de matéria seca $(\mathrm{kg})$;

$\mathrm{CFDN}=$ consumo diário de FDN $(\mathrm{kg})$.

Para caracterizar o ambiente térmico, foram instalados, nas baias, termo-higrômetro para registro da temperatura do ar $\left({ }^{\circ} \mathrm{C}\right)$ e da umidade 
relativa do ar (\%), e termômetro de globo negro para determinação do índice de temperatura do globo negro e umidade $(\mathrm{ITGU}=\mathrm{TGN}+0,36 *$ (Tpo) + 41,5), conforme metodologia descrita por Buffington et al. (1981). O índice de temperatura e umidade foi calculado segundo metodologia proposta por Baeta e Sousa (2010): $(\mathrm{ITU}=\mathrm{Ta}+0,36 \mathrm{Tpo}+41,2) . \mathrm{O}$ ponto de orvalho foi calculado pela fórmula: $\mathrm{TPO}=$ ${ }^{8} \sqrt{\mathrm{UR}} / 100 *[112+(0,9 * \mathrm{~T})]+(0,1 * \mathrm{~T})-112$.

No $11^{\circ}$ dia de cada período experimental, foram avaliados os parâmetros fisiológicos aferidos no turno da manhã, às $10 \mathrm{~h}$, e no turno da tarde, às $15 \mathrm{~h}$.

A frequência respiratória (FR) foi determinada pela contagem dos movimentos do flanco de cada animal. A frequência cardíaca (FC) foi aferida pela contagem dos batimentos cardíacos por meio de um estetoscópio. E a temperatura retal (TR) foi obtida utilizando-se um termômetro clínico introduzido no reto do animal de forma que o bulbo ficasse em contato com a mucosa por dois minutos.

Os dados foram submetidos à análise de variância e regressão, que utilizou como fonte de variação o efeito das dietas. Os dados das respostas fisiológicas referentes aos turnos foram submetidos à comparação de médias pelo teste de Tukey, empregando-se o programa estatístico SAS (Statistical..., 2008).

\section{RESULTADOS E DISCUSSÃO}

A substituição do farelo de soja por torta de amendoim não influenciou $(\mathrm{P}>0,05)$ as eficiências de ingestão e ruminação, expressas em kg MS/h e kg FDN/h (Tab. 4). A ausência de efeito é atribuída ao fato do teor de FDN das dietas serem semelhante (Tab. 3), pois a ingestão voluntária de matéria seca é relacionada ao teor de FDN da dieta, cuja fermentação e passagem pelo retículo-rúmen são mais lentas que outras frações nutricionais (Barbosa et al., 2006).

Correia et al. (2012), ao avaliarem as tortas de dendê, amendoim e girassol na dieta com relação volumoso:concentrado $(65: 35)$ na forma de dieta total para novilhos Holandês x Zebu, também não encontraram efeito das tortas sobre as eficiências de ingestão e de ruminação da matéria seca e fibra em detergente neutro.

O tempo de mastigações merícicas (TMMb) e o número de mastigações merícicas por bolo (NMMb), assim como o número de bolos ruminados por dia (NBRd) e o tempo de mastigação total por dia (TMT), não foram influenciados $(\mathrm{P}>0,05)$ pelos níveis de torta de amendoim no concentrado das dietas (Tab. 5).

Como as atividades de mastigação estão associadas à taxa de secreção salivar, à solubilização de componentes do alimento e à quebra de partículas (Mendes Neto et al., 2007), estas variáveis não foram influenciadas durante a ruminação.

Os níveis de substituição do farelo de soja por torta de amendoim das dietas não influenciaram (P>0,05) o tempo despendido as atividades de ingestão e ócio (Tab. 6).

Desta forma, na relação volumoso:concentrado (70:30), os animais não têm preferência alimentar pelo farelo de soja ou pela torta de amendoim do concentrado na dieta misturada, pois não houve comportamento ingestivo seletivo das dietas.

Tabela 4. Eficiência de ingestão (EIF) e eficiência de ruminação (ERU) por novilhos submetidos a dietas com níveis de torta de amendoim

\begin{tabular}{|c|c|c|c|c|c|c|c|c|}
\hline \multirow[t]{2}{*}{ Item } & \multicolumn{5}{|c|}{$\begin{array}{l}\text { Níveis de substituição do farelo de soja por torta de } \\
\text { amendoim }(\%)\end{array}$} & \multirow[t]{2}{*}{${ }^{1} \mathrm{EPM}$} & \multicolumn{2}{|c|}{${ }^{4}$ Valor $\mathrm{P}$} \\
\hline & 0 & 25 & 50 & 75 & 100 & & ${ }^{2} \mathrm{~L}$ & ${ }^{3} \mathrm{Q}$ \\
\hline \multicolumn{9}{|c|}{ Matéria seca } \\
\hline $\mathrm{EFI}(\mathrm{kg} / \mathrm{h})$ & 2,60 & 2,63 & 2,47 & 2,65 & 2,68 & 0,17 & 0,77 & 0,61 \\
\hline ERU $(\mathrm{kg} / \mathrm{h})$ & 1,46 & 1,47 & 1,45 & 1,38 & 1,41 & 0,05 & 0,22 & 0,91 \\
\hline \multicolumn{9}{|c|}{ Fibra em detergente neutro } \\
\hline $\mathrm{EFI}(\mathrm{kg} / \mathrm{h})$ & 1,41 & 1,42 & 1,35 & 1,44 & 1,47 & 0,09 & 0,62 & 0,59 \\
\hline ERU $(\mathrm{kg} / \mathrm{h})$ & 0,78 & 0,80 & 0,79 & 0,75 & 0,77 & 0,03 & 0,55 & 0,84 \\
\hline
\end{tabular}

${ }^{1} \mathrm{EPM}=$ erro padrão da média. ${ }^{2} \mathrm{~L}=$ significância para efeito linear. ${ }^{3} \mathrm{Q}=$ significância para efeito quadrático. ${ }^{4}$ Valor-P $=$ probabilidade significativa ao nível de $5 \%$. 
Tabela 5. Tempo de mastigações merícicas (TMMb), número de mastigações merícicas (NMMb), número de bolos ruminados por dia (NBRd) e tempo de mastigação total por dia (TMT) por novilhos submetidos a dietas com níveis de torta de amendoim no concentrado

\begin{tabular}{|c|c|c|c|c|c|c|c|c|}
\hline \multirow[t]{2}{*}{ Item } & \multicolumn{5}{|c|}{$\begin{array}{l}\text { Níveis de substituição do farelo de soja por torta } \\
\text { de amendoim }(\%)\end{array}$} & \multirow[t]{2}{*}{${ }^{1} \mathrm{EPM}$} & \multicolumn{2}{|c|}{${ }^{4}$ Valor P } \\
\hline & 0 & 25 & 50 & 75 & 100 & & ${ }^{2} \mathrm{~L}$ & ${ }^{3} \mathrm{Q}$ \\
\hline TMMb (s/bolo) & 59,40 & 59,40 & 58,40 & 57,00 & 56,20 & 4,73 & 0,54 & 0,91 \\
\hline $\mathrm{NMMb}\left(\mathrm{n}^{\circ} / \mathrm{bolo}\right)$ & 58,20 & 57,20 & 56,20 & 55,80 & 53,80 & 3,40 & 0,33 & 0,91 \\
\hline NBRd (nºldia) & 589 & 579 & 588 & 599 & 609 & 37,91 & 0,61 & 0,77 \\
\hline TMT (min/dia) & 897 & 881 & 889 & 862 & 854 & 39,17 & 0,40 & 0,90 \\
\hline
\end{tabular}

${ }^{1} \mathrm{EPM}=$ erro padrão da média. ${ }^{2} \mathrm{~L}=$ significância para efeito linear. ${ }^{3} \mathrm{Q}=$ significância para efeito quadrático. ${ }^{4}$ Valor-P $=$ probabilidade significativa ao nível de $5 \%$.

Tabela 6. Tempo em minutos despendido nas atividades de ingestão, ruminação e ócio nos turnos da manhã, tarde, noite e madrugada por novilhos submetidos a dietas com torta de amendoim no concentrado

\begin{tabular}{|c|c|c|c|c|c|c|c|c|}
\hline \multirow[t]{2}{*}{ Turno } & \multicolumn{5}{|c|}{$\begin{array}{l}\text { Níveis de substituição do farelo de soja por torta de } \\
\text { amendoim (\%) }\end{array}$} & \multirow{2}{*}{${ }^{1} \mathrm{EPM}$} & \multicolumn{2}{|c|}{${ }^{4}$ Valor P } \\
\hline & 0 & 25 & 50 & 75 & 100 & & ${ }^{2} \mathrm{~L}$ & ${ }^{3} \mathrm{Q}$ \\
\hline \multicolumn{9}{|c|}{ Tempo de ingestão } \\
\hline Manhã & 102 & 101 & 123 & 105 & 107 & 8,26 & 0,62 & 0,53 \\
\hline Tarde & 127 & 127 & 129 & 123 & 126 & 12,68 & 0,88 & 0,99 \\
\hline Noite & 46 & 43 & 38 & 45 & 30 & 9,97 & 0,36 & 0,63 \\
\hline Madrugada & 46 & 50 & 42 & 22 & 35 & 11,02 & 0,17 & 0,40 \\
\hline \multicolumn{9}{|c|}{ Tempo de ruminação } \\
\hline Manhã & 123 & 123 & 88 & 101 & 96 & 11,55 & 0,06 & 0,12 \\
\hline Tarde & 109 & 104 & 111 & 119 & 108 & 8,68 & 0,65 & 0,86 \\
\hline Noite & 176 & 158 & 164 & 154 & 176 & 15,29 & 0,94 & 0,54 \\
\hline Madrugada & 168 & 175 & 194 & 193 & 176 & 11,31 & 0,39 & 0,23 \\
\hline \multicolumn{9}{|c|}{ Tempo de ócio } \\
\hline Manhã & 135 & 137 & 148 & 154 & 157 & 14,23 & 0,17 & 0,39 \\
\hline Tarde & 123 & 129 & 120 & 118 & 126 & 8,99 & 0,86 & 0,94 \\
\hline Noite & 138 & 158 & 158 & 161 & 154 & 18,58 & 0,54 & 0,63 \\
\hline Madrugada & 147 & 135 & 125 & 145 & 149 & 13,23 & 0,74 & 0,43 \\
\hline
\end{tabular}

${ }^{1} \mathrm{EPM}=$ erro padrão da média. ${ }^{2} \mathrm{~L}=$ significância para efeito linear. ${ }^{3} \mathrm{Q}=$ significância para efeito quadrático. ${ }^{4}$ Valor-P $=$ probabilidade significativa ao nível de $5 \%$.

Correia et al. (2012) testaram as tortas de dendê, amendoim e girassol com relação volumoso:concentrado $(65: 35)$ na forma de dieta total para novilhos Holandês x Zebu e também não constataram efeito das tortas de amendoim e girassol sobre o tempo de ingestão. O tempo médio de ingestão neste trabalho (313min) foi inferior ao tempo de ingestão (330min/dia) observado por Correia et al. (2012), sendo atribuída a fração concentrada que compõe $35 \%$ da dieta na forma de mistura total, enquanto no presente trabalho compõe $30 \%$ na mistura da dieta (Tab. 1). A maior proporção de concentrado eleva o teor de CNF da dieta, fração nutricional que promove um incremento de energia à fermentação ruminal, permitindo a elevação do consumo de MS e do tempo destinado à atividade de ingestão.

Os níveis de torta de amendoim das dietas não influenciaram $(\mathrm{P}>0,05)$ o número de períodos de ingestão e ruminação (Tab. 7). 
Oliveira et al.

Tabela 7. Número de períodos de ingestão, ruminação e ócio nos turnos da manhã, tarde, noite e madrugada por novilhos submetidos a dietas com torta de amendoim no concentrado

\begin{tabular}{|c|c|c|c|c|c|c|c|c|}
\hline \multirow[t]{2}{*}{ Turno } & \multicolumn{5}{|c|}{$\begin{array}{c}\text { Níveis de substituição do farelo de soja por torta de } \\
\text { amendoim }(\%)\end{array}$} & \multirow{2}{*}{${ }^{1} \mathrm{EPM}$} & \multicolumn{2}{|c|}{${ }^{4}$ Valor $\mathrm{P}$} \\
\hline & 0 & 25 & 50 & 75 & 100 & & ${ }^{2} \mathrm{~L}$ & ${ }^{3} \mathrm{Q}$ \\
\hline \multicolumn{9}{|c|}{ Número de período de ingestão } \\
\hline Manhã & 4,8 & 4,6 & 7,0 & 4,8 & 5,6 & 0,81 & 0,54 & 0,63 \\
\hline Tarde & 5,2 & 6,4 & 6,0 & 5,2 & 7,0 & 0,94 & 0,42 & 0,71 \\
\hline Noite & 2,6 & 2,8 & 2,4 & 3,2 & 3,2 & 0,68 & 0,45 & 0,72 \\
\hline Madrugada & 2,6 & 3,0 & 2,4 & 1,8 & 3,0 & 0,52 & 0,82 & 0,74 \\
\hline \multicolumn{9}{|c|}{ Número de período de ruminação } \\
\hline Manhã & 3,8 & 4,0 & 3,2 & 3,2 & 3,6 & 0,37 & 0,34 & 0,46 \\
\hline Tarde & 3,4 & 3,2 & 3,6 & 3,8 & 3,6 & 0,56 & 0,59 & 0,86 \\
\hline Noite & 5,2 & 5,4 & 4,8 & 4,0 & 5,4 & 0,45 & 0,53 & 0,41 \\
\hline Madrugada & 4,8 & 5,0 & 4,4 & 4,4 & 5,0 & 0,53 & 0,90 & 0,77 \\
\hline \multicolumn{9}{|c|}{${ }^{2}$ Número de período de ócio } \\
\hline${ }^{5}$ Manhã & 6,3 & 6,9 & 7,5 & 8,0 & 8,6 & 0,80 & 0,04 & 0,07 \\
\hline Tarde & 7,4 & 7,4 & 8,0 & 8,0 & 8,6 & 0,84 & 0,26 & 0,52 \\
\hline Noite & 6,4 & 6,4 & 6,6 & 6,4 & 7,4 & 0,62 & 0,34 & 0,51 \\
\hline Madrugada & 6,6 & 5,8 & 5,4 & 6,4 & 6,4 & 0,53 & 0,91 & 0,34 \\
\hline
\end{tabular}

A torta de amendoim é um subproduto muito susceptível à contaminação por aflatoxinas. Neste trabalho, continha $22,18 \mu \mathrm{g} / \mathrm{kg}$ de micotoxinas referentes à soma das aflatoxinas B1, B2, G1 e G2, que constituem as principais toxinas produzidas pelos fungos Aspergillus flavus, Aspergillus parasiticus, Aspergillus nomius (Creppy, 2002).

Observou-se efeito linear crescente do número de períodos de ócio no turno da manhã $(\mathrm{P}<0,05)$ com a substituição do farelo de soja por torta de amendoim no concentrado da dieta (Tab. 7). Como as atividades comportamentais são excludentes, os animais interrompiam a atividade de ingestão para o ócio rejeitando mais a dieta. A redução da aceitabilidade neste turno pode ser atribuída ao fato das sobras do oferecido no dia serem recolhidas às $8 \mathrm{~h} 40$. $\mathrm{O}$ crescimento de fungos é determinado pelo teor de umidade, aeração (Marcia e Lazzari, 1998). Desta forma, a saliva dos animais e o prolongamento da deterioração aeróbia dos alimentos ocasionaram alterações indesejáveis no sabor, limitando sua aceitação.

Os elevados valores de temperatura do ar e umidade relativa do ar ocasionaram elevados índices do ITGU e ITU (Tab. 8). De acordo com Baêta e Sousa (2010) os valores de ITGU até 74, de 74 a 78 , de 79 a 84 e acima de 84 definem situação de conforto, de alerta, de perigo e de emergência, respectivamente, para ruminantes.

Com relação ao ITU, segundo Baêta e Sousa (2010), valores inferiores ou iguais a 70, de 71 a 78 , de 79 a 83 e acima de 83 indicam condições normal, crítica, de perigo e de emergência, respectivamente. Sendo assim, os resultados de ITGU e ITU obtidos neste estudo indicam que os animais estiveram em situação crítica ou de alerta no período diurno, ocasionando desconforto térmico.

Tabela 8. Valores médios das variáveis ambientais observados durante o experimento

\begin{tabular}{lccc}
\multicolumn{1}{c}{ Variáveis climáticas } & Manhã & Tarde & Média geral \\
\hline Temperatura do ar $\left({ }^{\circ} \mathrm{C}\right)$ & 28,7 & 32,2 & 30,4 \\
Umidade relativa do ar $(\%)$ & 76,9 & 54,2 & 65,5 \\
Índice de temperatura do globo negro e umidade $(\%)$ & 74,1 & 76,8 & 75,4 \\
Índice de temperatura e umidade (\%) & 70,1 & 73,6 & 71,8 \\
\hline
\end{tabular}


Os bovinos são animais homeotérmicos, produzem constantemente calor para exercer suas funções fisiológicas e constantemente dissipam calor. O calor é perdido em função da superfície corporal, um corpo maior perde menos calor que um corpo menor devido à menor relação superfície/volume. Desta forma, os ruminantes de grande porte, como os bovinos, são capazes de armazenar durante o turno diurno mais calor corporal que os ruminantes de pequeno porte. Este fato é corroborado por Martello et al. (2004) e Cunha et al. (2007), os quais observaram temperatura retal mais alta no turno da tarde em relação ao turno da manhã em bovinos.

Sabendo-se que a temperatura retal reflete o acúmulo de calor do ambiente e da produção interna, como a temperatura retal dos bovinos no turno da tarde foi semelhante ao turno da manhã (Tab. 9), pode-se considerar que os animais encontram-se dentro da faixa de conforto térmico e que os fatores ambientais não influenciaram o consumo de matéria seca. Este fato é corroborado pela média de temperatura retal $\left(38,9^{\circ} \mathrm{C}\right)$ que está dentro da faixa de normalidade (38 a $39,5^{\circ} \mathrm{C}$ ) para bovinos (Ferreira et al., 2006).

Não houve efeito $(\mathrm{P}>0,05)$ da temperatura retal e da frequência respiratória com a elevação dos níveis de torta de amendoim nas dietas. Van Soest (1994) citou que o tempo de ruminação é influenciado pela natureza da dieta e que este aumenta de acordo com o conteúdo de FDN. Desta forma, como o tempo de ruminação não foi influenciado pelas dietas constituídas de níveis de torta de amendoim (Tab. 6), a quantidade desta fração a ser fermentada e a produção de calor endógeno são semelhantes, não reduzindo a temperatura retal e a frequência respiratória. A redução do teor de fibra da dieta gera incremento calórico menor ao diminuir a produção de acetato no rúmen, reduzindo a produção de calor endógeno (Goularte et al., 2011).

Tabela 9. Valores de temperatura retal em ${ }^{\circ} \mathrm{C}$, frequência respiratória em movimentos por minuto (mov/min) e frequência cardíaca em batimentos por minuto (bat/min) nos turnos da manhã e tarde de novilhos submetidos a dietas com torta de amendoim no concentrado

\begin{tabular}{|c|c|c|c|c|c|c|c|c|}
\hline \multirow[t]{2}{*}{ Turno } & \multicolumn{5}{|c|}{$\begin{array}{l}\text { Níveis de substituição do farelo de soja por torta de } \\
\text { amendoim }(\%)\end{array}$} & \multirow{2}{*}{${ }^{1} \mathrm{EPM}$} & \multicolumn{2}{|c|}{${ }^{4}$ Valor $\mathrm{P}$} \\
\hline & 0 & 25 & 50 & 75 & 100 & & ${ }^{2} \mathrm{~L}$ & ${ }^{3} \mathrm{Q}$ \\
\hline \multicolumn{9}{|c|}{ Temperatura retal $\left({ }^{\circ} \mathrm{C}\right)$} \\
\hline Manhã & $38,8 \mathrm{a}$ & $39,0 \mathrm{a}$ & $39,1 \mathrm{a}$ & $39,0 \mathrm{a}$ & $39,0 \mathrm{a}$ & 0,10 & 0,44 & 0,38 \\
\hline Tarde & $38,9 \mathrm{a}$ & $38,7 \mathrm{a}$ & $38,8 \mathrm{a}$ & $38,8 \mathrm{a}$ & $38,8 \mathrm{a}$ & 0,10 & 0,60 & 0,61 \\
\hline \multicolumn{9}{|c|}{ Frequência respiratória (mov/min) } \\
\hline Manhã & $60,8 \mathrm{a}$ & $52,8 \mathrm{a}$ & $54,4 \mathrm{a}$ & $64,0 \mathrm{a}$ & $53,6 \mathrm{a}$ & 6,77 & 0,88 & 0,98 \\
\hline Tarde & $55,2 \mathrm{a}$ & $52,0 \mathrm{a}$ & $53,6 \mathrm{a}$ & $57,6 \mathrm{a}$ & $52,8 \mathrm{a}$ & 4,11 & 0,95 & 1,00 \\
\hline \multicolumn{9}{|c|}{ Frequência cardíaca (bat/min) } \\
\hline Manhã & $89,6 a$ & $90,4 a$ & $84,8 \mathrm{a}$ & $85,6 \mathrm{a}$ & $84,0 \mathrm{a}$ & 2,92 & 0,10 & 0,27 \\
\hline Tarde & $88,0 \mathrm{a}$ & $84,0 \mathrm{a}$ & $85,6 a$ & $87,2 \mathrm{a}$ & $86,4 a$ & 1,95 & 1,00 & 0,71 \\
\hline
\end{tabular}

Médias nas colunas seguidas por letras iguais não diferem $(\mathrm{P}>0,05)$ pelo teste Tukey.

${ }^{1} \mathrm{EPM}=$ erro padrão da média. ${ }^{2} \mathrm{~L}=$ significância para efeito linear. ${ }^{3} \mathrm{Q}=$ significância para efeito quadrático. ${ }^{4}$ Valor-P $=$ probabilidade significativa ao nível de $5 \%$.

Correia et al. (2012), ao avaliarem os parâmetros fisiológicos de novilhos Holandês $x$ Zebu alimentados com dieta contendo torta de dendê, amendoim e girassol, não constataram efeito das tortas sobre a dieta testemunha constituída com farelo de soja em relação às variáveis temperatura retal e frequência respiratória.

Não houve efeito $(\mathrm{P}>0,05)$ dos níveis de substituição do farelo de soja por torta de amendoim na dieta sobre os batimentos cardíacos. A torta não sofre extração do óleo pelo uso de solventes, sendo constituída de maior teor de EE que não é fermentável no rúmen, o que poderia vir a reduzir o calor endógeno produzido pela fermentação ruminal, entretanto esta hipótese não ocorreu pela baixa ingestão da torta devido à alta relação volumoso:concentrado (70:30). Correia et al. (2012), ao avaliarem os parâmetros fisiológicos de novilhos alimentados 
com dietas contendo torta de dendê, girassol e amendoim em relação volumoso:concentrado (65:35), constataram frequência cardíaca mais alta para a dieta testemunha com farelo de soja, o que está relacionado ao baixo teor de extrato etéreo do farelo de soja, assim outras frações nutricionais tornam-se mais fermentecíveis no rúmen, produzindo mais calor endógeno. Desta forma, a utilização das tortas na dieta ocasiona efeito positivo ao bem-estar dos animais.

Em relação aos batimentos por minuto, estes se encontram no limite superior ao valor de referência para bovinos, que, de acordo com Detweiler (1996), varia entre 48 e 80 batimentos por minuto. Isto é atribuído à movimentação dos animais ao serem deslocados da baia ao brete para avaliação dos parâmetros fisiológicos.

\section{CONCLUSÕES}

A torta de amendoim contém bom valor nutricional e, por conter aflatoxinas quando é fornecido em alta relação, volumoso $x$ concentrado, pode substituir totalmente o farelo de soja na dieta de novilhos, pois ocasiona comportamento ingestivo e respostas fisiológicas semelhantes.

\section{REFERÊNCIAS}

BAÊTA, F.C.; SOUZA, C.F. Ambiência em edificações rurais: Conforto animal. 2.ed. Viçosa: UFV, 2010. 269p.

BARBOSA, N.G.S.; LANA, R.P.; HAM, N.J. Consumo e fermentação ruminal de fibras em função de suplementação alimentar energética e proteica em novilhos. Rev. Bras. Zootec., v.30, p.1558-1565, 2006.

BUFFINGTON, D.E.; COLAZZO-AROCHO, A.; CANTON, G.H.; PITT, D. Black globehumidity index (BGHI) as confort equacion for dairy cows. Trans. Asae, v.24, p.711-714, 1981.

BURGER, P.J.; PEREIRA, J.C.; QUEIROZ, A.C. et al. Comportamento ingestivo em bezerros holandeses alimentados com dietas contendo diferentes níveis de concentrado. Rev. Bras. Zootec., v.29, p.236-242, 2000.
CORREIA, B.R.; OLIVEIRA, R.L.; JAEGER, S.M.P.L. et al. Consumo, digestibilidade e pH ruminal de novilhos submetidos a dietas com tortas oriundas da produção do biodiesel em substituição ao farelo de soja. Arq. Bras. Med. Vet. Zootec., v.63, p.356-363, 2011.

CORREIA, B.R.; OLIVEIRA, R.L.; JAEGER, S.M.P.L. et al. Comportamento ingestivo e parâmetros fisiológicos de novilhos alimentados com tortas do biodiesel em substituição ao farelo de soja. Arch. Zootec., v.61, p.1-11, 2012.

CREPPY, E.E. Update of survey, regulation and toxic effects of mycotoxins in Europe. Toxicol. Lett., v.127, p.19-28, 2002.

CUNHA, N.F.V.C.; CAMPOS, O.F.; PEREIRA, J.C. et al. Desempenho, variáveis fisiológicas e comportamento de bezerros mantidos em diferentes instalações: época chuvosa. Rev. Bras. Zootec., v.36, p.1140-1146, 2007.

DETWEILER, D.K. Regulação cardíaca. In: DUKES, H.H. (Ed). Fisiologia dos animais domésticos. Rio de Janeiro: Guanabara Koogan, 1996. 856p.

FERREIRA, F.; PIRES, M.F.A.; MARTINEZ, M.L. et al. Parâmetros fisiológicos de bovinos cruzados submetidos ao estresse calórico. Arq. Bras. Med. Vet. Zootec., v.58, p.732-738, 2006.

GOULARTE, S.R.; ÍTAVO, L.C.V.; ÍTAVO, C.C.B.F. et al. Comportamento ingestivo $\mathrm{e}$ digestibilidade de nutrientes em vacas submetidas a diferentes níveis de concentrado. Arq. Bras. Med. Vet. Zootec., v.63, p.414-422, 2011.

JOHNSON, T.R.; COMBS, D.K. Effects of prepartum diet, inert rumen bulk, and dietary polyethylene glycol, on dry matter intake of lactating dairy cows. J. Dairy Sci., v.74, p.933944, 1991.

MACEDO JUNIOR, G.L.; FRANÇA, P.M.; ASSIS, R.M. et al. Níveis de fibra em detergente neutro forrageiro na alimentação de ovelhas Santa Inês gestantes. Arq. Bras. Med. Vet. Zootec., v.61, p.196-202, 2009.

MARCIA, B.A.; LAZZARI, F.A. Monitoramento de Fungos em milho em grão, grits e fubá. Cienc. Tecnol. Aliment., v.18, p.363-367, 1998. 
MARTELLO, L.S.; SAVASTANO JUNIOR, H.; SILVA, S.L.; TITTO, E.A.L. Respostas fisiológicas e produtivas de vacas holandesas em lactação submetidas a diferentes ambientes. Rev. Bras. Zootec., v.33, p.181-191, 2004.

MENDES NETO, J.; CAMPOS, J.M.S.; VALADARES FILHO, S.C. et al. Comportamento ingestivo de novilhas leiteiras alimentadas com polpa cítrica em substituição ao feno de capim-tifton 85. Rev. Bras. Zootec., v.36, p.618-625, 2007.

NUTRIENT requirements of dairy cattle. 7.ed. Washington: National Academy of Sciences, 2001.381p.

OFFICIAL methods of analysis. 16.ed. Washington: AOAC, 1995. 186p.
SNIFFEN, C.J.; O'CONNOR, D.J.; VAN SOEST, P.T. et al. A net carbohydrate and protein system for evaluating cattle diets: carbohydrate and protein availability. J. Anim. Sci., v.70, p.3562-3577, 1992.

STATISTICAL Analysis Sistem - SAS Institute Inc. The SAS System, release 9.2. SAS Institute Inc., Cary:NC, 2008.

VAN SOEST, P.J. Nutritional ecology of the ruminant. 2.ed. Ithaca: Comstock, 1994. 476p.

VAN SOEST, P.J.; ROBERTSON, J.B.; LEWIS, B.A. Methods for dietary fiber, neutral detergent fiber, and nonstarch polysaccharides in relation to animal nutrition. J. Dairy Sci., v.74, p.35833597, 1991. 